\title{
Research on Product Development and Design Quality Control Based on QFD
}

\author{
AiZu Chen \\ College of Economics and Management \\ Hebei University of Science and Technology \\ Shijiazhuang, Hebei, China \\ e-mail: Chenaizu@ souhu.com
}

\begin{abstract}
Quality function deployment (QFD) using the design and manufacturing requirements. This theory based on the QFD method, JK company manufactures drilling rigs, for example, categorizing customers, through the establishment of "House of quality" model analysis of quality characteristics of different customer needs to improve and control the quality of the product.
\end{abstract}

Keywords-quality function deployment(QFD); house of quality; quality control ;customer demand;weight

\section{INTRODUCTION}

Today, the enterprise in order to guarantee their products to be accepted by the customer, they must indepth study and analyze the customer's needs, and translate customer needs into product development and design of the various quality characteristics, then take these quality characteristics into product development and production process, and eventually converted into product features, truly reflects customer demand.

Quality Function Deployment (referred to as QFD) is a proposed in 1967 by Japanese professor Akao structured method for product development based on customer requirements, it contributes to the product development team to develop and the process of product design pays more attention to the customer's demand. It has been widely used in the fields of manufacturing industry, service industry, new industry and teaching etc.. Murray, Zhang Jiatai take an enterprise producing refrigerator customer demand as an example, establishes the evaluation model, and related factors in house of quality matrix is constructed to quantitatively determine the user needs, and finally to analyze the quality problems that may exist; Sun Hong introduces QFD in customer satisfaction research established customer satisfaction evaluation of quality house model;Liu Shuqing, Jin Yan aiming at the problem of project design process in the application of QFD technology is weak, the sub process interface design fuzzy, put forward the method and procedure of using QFD technology in the design process.

Although in the past many people studying QFD method, the use of QFD method to translate customer needs into design objectives and key quality assurance, but currently using the theory of QFD categorizes customer research is still rare. This theory based on QFD method, categorizing customers, through the establishment of "House of quality" model analysis of quality characteristics of the different needs of customers, so as to improve and control the quality of the product.

\author{
SuChao Hao \\ College of Economics and Management \\ Hebei University of Science and Technology \\ Shijiazhuang, Hebei, China \\ e-mail: haosuchao@163.com
}

\section{QFD IMPROVEMENT}

The core idea of QFD method is to pay attention to the product from the initial feasibility study to the production process of the product to customer demanddriven,emphasizing the market customer demand explicitly into product development manager, designer, manufacture department and production planning department and other relevant personnel to perform specific information, which ensuring enterprises can eventually produce products that meet customer needs.

QFD II differs from the traditional quality function deployment, it is a tool in quality function deployment based on traditional improvement.QFD II is to classify customers and identify customer needs, although different customers on product quality requirements are different, but they also have certain commonalities between qualitative characteristic.The common quality characteristics implement into the development and production process of the product, eventually into the product characteristics, truly reflects the customer demand.

\section{A. House of Quality concept}

"The house of quality " concept first proposed by the USA scholars J.R.HUSER and D.CLAUSING in 1988 .The house of quality is the core of QFD, is used to assess the description of customer demand, design requirements, the target value and competitiveness of technology planning matrix. The house of quality in this paper is different from the house of quality in the past, starting from customers categories, to convert all kinds of customer needs into product development engineering properties required in the process. The basic principle of figure 1 .

\section{B. The generation process of house of quality}

\section{1) Determine customer needs and weight}

According to the investigation and analysis of customer information, customer classification on the left wall of house of quality, according to different types of customers for the company's value for important score, statistical processing, the customer importance for the average is $x_{i}(\mathrm{i}=1,2, \ldots, \mathrm{n})$, importance weights $a_{i}$ of customer for class $\mathrm{i}$ :

$$
\mathrm{a} i=x_{i} / \sum_{i=1}^{n} x_{i}
$$


Then determine the types of customer demand and the demand of $S_{i}$, the user needs the weight of $w i$ class i customer as:

$$
w_{i}=a_{i} \cdot S i
$$

The various types of customer demand and the corresponding right to the sequence in the left wall of house of quality.

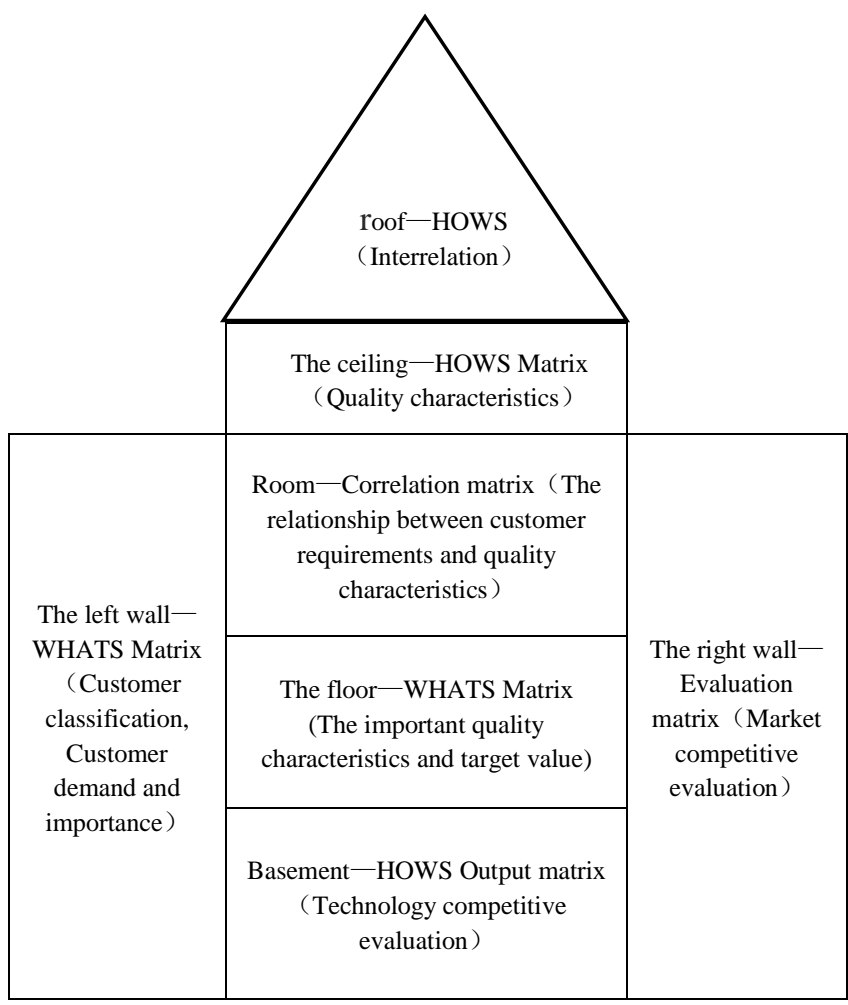

Figure 1. The structure of house of quality

\section{2) To determine quality characteristics}

Weights of customer needs analysis, identifying diverse customer needs and appropriate product quality attributes, and the various quality characteristics are listed in the house of quality on the ceiling.

3) To determine the relation matrix of house of quality

The relationship between quality requirements of customers and the corresponding product quality characteristics and intensity, with the following symbols in the house of quality in the room, can also be used more types of symbols or other symbols:

- Strong relationship

- Moderate relationship

$\Delta \quad$ Weak relationship

Blank No relationship

Intersection grid item $i^{\prime}$ customer demand in the $\mathrm{i}$ class customers where the line with the $\mathrm{j}$ quality characteristics of column, symbol relationship item i' customer needs the $\mathrm{i}$ class customers for the $\mathrm{j}$ quality characteristics to fill, formed the relation matrix of house of quality.

\section{4) To determine the importance of quality characteristics}

The QFD method by weighted method to quantify the importance of quality characteristics. The method is: on the relationship between matrix symbol according to relationship to the points, generally according to the practical situation and the scores are given, such as to as follows:

$$
\begin{array}{ll}
- & 5 \text { points } \\
\circ & 3 \text { points } \\
\Delta & 1 \text { points }
\end{array}
$$

Blank 0 points

So it formed a relationship matrix [Rij], the $\mathrm{j}$ quality characteristics of ${ }^{m_{j}}$ is weighted ${ }^{w i}$ for every Rij . And, that is:

$$
m_{j}=\sum_{\mathrm{i}=1}^{n} \mathrm{~W}_{i} \cdot R_{i j}
$$

The importance of $m_{j}$ quality specification for the quality characteristics of the weight, the $\mathrm{j}$ quality characteristics number $w_{i}$ :

$$
w_{j}=m_{j} / \sum_{j=1}^{n} m_{j}
$$

The quality characteristics of each weight ${ }^{\mathcal{W}_{i}}$ down in house of quality above the ground, according to the various weights of quality characteristics can be determined which is the key quality characteristics and important quality characteristics.

\section{5) Determine the quality plan}

The first step is to compare.For the improvement of products, the current products comparing with competitors' similar products on the market,comparing advantages and disadvantages from the perspective of customer demand ,as the basis of new product quality planning

The second step is to develop quality plans to improve the products.Comparing this enterprise product quality level and competition in the market similar products quality level, so as to determine the level of the enterprise to improve the quality of the product to achieve, which improve the quality of product plan.

\section{6) Quality characteristics of correlation matrix}

Quality house and the top triangle matrix, it is used to illustrate between the quality characteristic and quality characteristic of the associated matrix.The relationship between the quality characteristic and quality characteristic has a strong positive correlation, positive correlation, irrelevant, strong negative correlation, negative correlation. The negative effect of improved if improving a quality characteristics will lead to another quality characteristics, said the relationship between quality characteristics are negatively correlated or strong negative correlation.On the other hand, called positive or strong positive correlation. The correlation between the quality characteristics of triangular matrix is generally use the following specific notation:

(a) Strong positive correlation

- Positive correlation

Blank Entirely unrelated

$X$ Negative correlation

XX Strong negative correlation 


\section{APPLICATION OF QFD METHOD IN JK COMPANY}

Hebei construction prospecting and drilling equipment Co., Ltd. (JK company) was founded in 1953, is a limited liability joint-stock enterprises, mainly produces water well drilling, oil drilling, coal-bed methane, shale gas drilling rig, drill rig, geothermal, drought resistance, reverse circulation drill rig, the rig, drilling equipment.To drill development and design of JK company as an example, generation of house of quality is described, see Figure 2.

\section{A. Determination of customer classification and customer requirements weights}

Firstly, companies currently have business dealings with customers for statistical analysis, divided them into four categories: platinum customers, gold customers, iron customers and lead customers.And then scored according to their respective benefits for the enterprise, to determine the weight of various customer of a110/30, a2 8/30, a37/30, a4 5/30.The platinum customers refers to the enterprise currently do business with the top of one of the main customers; Gold customers refers to the large customers currently do business with enterprises; Iron customers refers to the medium customers currently do business with enterprises; Lead customer refers to the small customers currently do business with enterprises.

After investigation and analysis of platinum customers demand mainly include strong overload capacity, high transmission efficiency, strong safety performance;Gold customers demand mainly include low failure rate, high control accuracy, low energy consumption;Iron customer needs are strong environmental adaptability, stable transmission, low repair rate; Lead customers demand mainly include small noise, low price, low repair rate. The relative importance of the various demands are as shown in table 1.

The weights of customer requirements is $w_{i}=a_{i} \cdot s_{i}$, as shown in figure 2.

\begin{tabular}{|c|c|c|c|c|c|c|c|c|c|c|c|c|}
\hline \multirow{2}{*}{$\begin{array}{l}\begin{array}{l}\text { Customer } \\
\text { classification }\end{array} \\
\text { Customer } \\
\text { demand }\end{array}$} & \multicolumn{3}{|c|}{ Platinum customers } & \multicolumn{3}{|c|}{ Gold customers } & \multicolumn{3}{|c|}{ Iron customer } & \multicolumn{3}{|c|}{ Lead customer } \\
\hline & $\begin{array}{c}\text { Strong } \\
\text { overload } \\
\text { capacity }\end{array}$ & $\begin{array}{c}\text { High } \\
\text { transmission } \\
\text { efficiency }\end{array}$ & $\begin{array}{l}\text { Strong } \\
\text { safety } \\
\text { perfor- } \\
\text { mance }\end{array}$ & $\begin{array}{l}\text { Low } \\
\text { failure } \\
\text { rate }\end{array}$ & $\begin{array}{c}\text { Good } \\
\text { control } \\
\text { precision }\end{array}$ & $\begin{array}{l}\text { Low } \\
\text { energy } \\
\text { consum- } \\
\text { ption }\end{array}$ & $\begin{array}{l}\text { Strong } \\
\text { adaptation } \\
\text { to the } \\
\text { environm- } \\
\text { ent }\end{array}$ & $\begin{array}{l}\text { High } \\
\text { transmis- } \\
\text { sion } \\
\text { efficiency }\end{array}$ & $\begin{array}{l}\text { Low } \\
\text { repair } \\
\text { rate }\end{array}$ & $\begin{array}{l}\text { Small } \\
\text { noise }\end{array}$ & $\begin{array}{l}\text { Low } \\
\text { price }\end{array}$ & $\begin{array}{l}\text { Low } \\
\text { repair } \\
\text { rate }\end{array}$ \\
\hline $\begin{array}{l}\text { Demand } \\
\text { importance } s_{i}\end{array}$ & 4 & 3 & 5 & 5 & 3 & 4 & 3 & 4 & 5 & 3 & 5 & 4 \\
\hline
\end{tabular}

TABLE I. THE DEMAND RELATIVELY IMPORTANT DEGREE

\section{B. To determine quality characteristics}

After classifying customers, identify customer development and design of the drilling quality characteristics are mainly the following: can be installed, balancing system, cooling system, operation control system, the monitoring system, automation, drilling motor form.

\section{Determining the relation matrix of customer requirements and quality characteristics}

Here, the relationship between customer requirements and quality characteristics respected by the numbers 5,3 , 1, 0,which indicates strong relationship, moderate relationship, weak relationship and no relationship.In Figure 2, class $\mathrm{i}$ customer requirements and the $\mathrm{j}$ quality characteristics of column was filled in the requirements of the degree symbol.Combined with the actual situation of the design and development of JK company, forming house of quality of figure 2 .

\section{Determining the importance of quality characteristics}

Application-independent collocation method, through the weighted average quantified to the importance of the develop design quality characteristics, so the importance of $m_{j}$ in the $\mathrm{j}$ quality characteristics for the Rij weighted $w_{i}$, namely

$$
m_{j}=\sum_{i=1}^{n} w_{i} \cdot R_{i j}
$$

On the normalized processing, the weight of the first item $\mathrm{j}$ development design quality as follows:

$$
w_{j}=m_{j} / \sum_{j=1}^{m} m_{j} \quad(\mathrm{~m}=1,2,3 \ldots 7)
$$

Specific as shown in figure 2.

\begin{tabular}{c|c}
\hline Quality characteristics & Weight \\
\hline Operation control system & 0.209 \\
\hline The degree of automation & 0.158 \\
\hline Cooling system & 0.152 \\
\hline Balance system & 0.144 \\
\hline Drilling Mazda form & 0.125 \\
\hline Operation monitoring & 0.11 \\
\hline Can be installed & 0.102 \\
\hline
\end{tabular}

Quality characteristics of important degree weight list, as shown in table 2 :

TABLE II. THE WEIGHT OF IMPORTANCE OF QUALITY CHARACTERISTICS 
As can be seen from the table in the development and design of the rig to determine their performance merits of the main quality parameters are: the degree of automation, cooling systems, balancing system, drilling Mazda form., which runs the control system, the degree of automation is the key to the design quality characteristics; cooling systems, mass balance system is an important design feature. These parameters directly affect the reliability of drilling rigs, service, cost, and other functional requirements.

\section{E. The quality planning of development and design}

1) Proving the product development and design planning in order to achieve the identify of customer 's satisfaction

Program development and design improvements required to achieve customer 's satisfaction, which is the demand for the product development and design to improve product improvements hope to achieve satisfaction of customer needs. JK rig design company combines customer needs ${ }^{y i}$ and competitor satisfaction rig design customer demand satisfaction $z i$, which determine the result shown in Figure 2.Among them:

$$
y^{\prime}=\operatorname{Max}\{y i, z i\}
$$

2) Improvement of product development and design to improve the level of rates.

The level of raising rate refers to the improvement of product development and design customer satisfaction relative to the original product development and design of the enterprise customer satisfaction rate of rise ${ }^{u i}$.

Among them $u i=y^{\prime} / y_{i}$, as shown in Figure 2.

3) Degree program is absolutely essential to determine the required quality.

So the plan calls for a degree of absolute importance as ${ }^{r i}$, then $r i=y_{i}{ }^{\prime} u i w i$.

4) Quality program requirements to determine the weights

Absolutely essential for the quality of the degree program requirements be normalized, we have plans to require quality weights $w i^{\prime}$ as follows:

$$
w_{i}=r_{i} / \sum_{i=1}^{n} r_{i} \quad(\mathrm{n}=1,2,3,4) 。
$$

Specifically as shown in Figure 2. Plans call for quality weight weights reflect the improved focus on product development and design, to guide the improvement of product development and design.

5) The key point to determine the quality of program requirements.

The key point plan calls for quality assessment is to evaluate the new plan calls for critical assessment of the quality points to improve the product quality requirements can become a design feature to improve the competitiveness of the design team from a strategic perspective. According $w i$ size, according to the $\mathrm{ABC}$ classification scheme to determine the critical point of the specific requirements of quality as shown in Figure 2. Design organizations should on this basis, according to ABC management key control method.

6) Plans to require improved product quality characteristics to determine the weights
The right to improve product design quality characteristics improved product weight is the weight of the customer program requirements derived. If the degree of importance $w i$ ' to improve the product from the customer program requirements starting weights, the plan to improve the quality of product development and design features $a^{j^{\prime}}$ are:

$$
a_{j^{\prime}}=\sum_{i=1}^{n} \mathrm{Wi}^{\prime} \cdot \mathrm{R}_{\mathrm{ij}} \quad(\mathrm{n}=1,2, \ldots 4)
$$

Product development and design plans for improving the quality characteristics of the absolute total degree of normalization $a^{\prime}$, we have the right product development plan to improve the quality characteristics of the weight $w^{\prime}$ is:

$$
w_{j^{\prime}}=a_{j^{\prime}} / \sum_{j=1}^{m} a_{j^{\prime}} \quad(\mathrm{m}=1,2, \ldots . .7)
$$

By improving the quality characteristics of the product development plan designed to calculate the weights can be seen as the key to the development of design quality characteristics operation control system, it is important to balance development and design quality attributes systems, cooling systems and automation.

\section{F. technological competitiveness assessment}

The design quality of products improved products and competitor products, JK company in all or the major quality characteristics to be scoring, as shown in Figure 2 Quality House basement shows. JK company product grade $u i$, new product marking $u i^{\prime}$, scoring $t i$ as competitors, technological competitiveness JK company product is:

$$
c=\sum_{j=1}^{m} w_{j^{\prime}} \cdot u_{i} \quad(\mathrm{j}=1,2,3, \ldots . .7)
$$

JK companies to improve technological competitiveness of products are:

$$
c^{\prime}=\sum_{j=1}^{m} w_{j^{\prime}} \cdot u i^{\prime} \quad(\mathrm{j}=1,2,3, \ldots \ldots .7)
$$

Technological competitiveness competitors are:

$$
y=\sum_{j=1}^{m} w_{j^{\prime}} \cdot \mathrm{t}_{i} \quad(\mathrm{j}=1,2,3, \ldots \ldots .7)
$$

From the above points, technological competitiveness improvement products while still cannot catch up with competitors technology competitiveness, technological competitiveness but has far exceeded the original products of JK company, this shows that the improved product advantage.

\section{CONCLUSIONS AND RECOMMENDATIONS}

Steps and methods proposed application of QFD process development and design techniques will improve and enhance the quality of its design team designed to provide some help, help to improve the success of the enterprise in the fierce market competition. Meanwhile, DFD technology for the development of subsequent stages of the design process -the preliminary design, construction design and construction process control is also a very effective tool. After the house of quality constructed, 
recommended its assessment, the assessment focuses on the relationship between the matrix and check whether the presence of empty rows or empty columns.

\section{REFERENCES}

[1] Adiano,C.\&Roth,A.V. Beyond the house of quality:dynamic QFD. Transactions of the fifths symposium on QFD, 1993,pp.450-458.

[2] Akao,Y. \& Mazur, G.H. The leading edge in QFD:Past,Present and future.International Journal of Quality and Reliability Management,2003,pp.20-35.

[3] Shen,X.X,Tan.K.C.,Xie,M.An Integrated Approach to Innovative Product Development Using Kano“s Model and QFD. Innovation Management , 2000

[4] Yuan Guilin. Research on the service quality of rural credit cooperatives in evaluation of Kano model and QFD based on the integration of Industrial and Commercial University Of Chongqing, 2011,pp45-47.

[5] Li Yongzhong. Experimental study on assessment of risk management framework of the QFD project and its validity. Based on the Nanjing University of Science and Technology ,2010.

[6] Ibo Poel. Methodological problems in QFD and directions for future development[J]. Research in Engineering Design , 2007.

[7] Xiang Yuanyuan. Research at the Zhejiang University, customer oriented product functional design approach based on QFD, 2010,pp.38-42.

[8] Geng Kaiyang. Shanghai Jiao Tong University green design method, modular series products based on QFD, 2013,pp.25-29.

[9] Wang J. Fuzzy outranking approach to prioritize design requirements in quality function deployment. International Journal of Production Research, 1999, pp899-916.

[10] Lai K Chan, Ming L. Wu. Prioritizing the technical measures in quality function deployment, 1998,pp 467-469

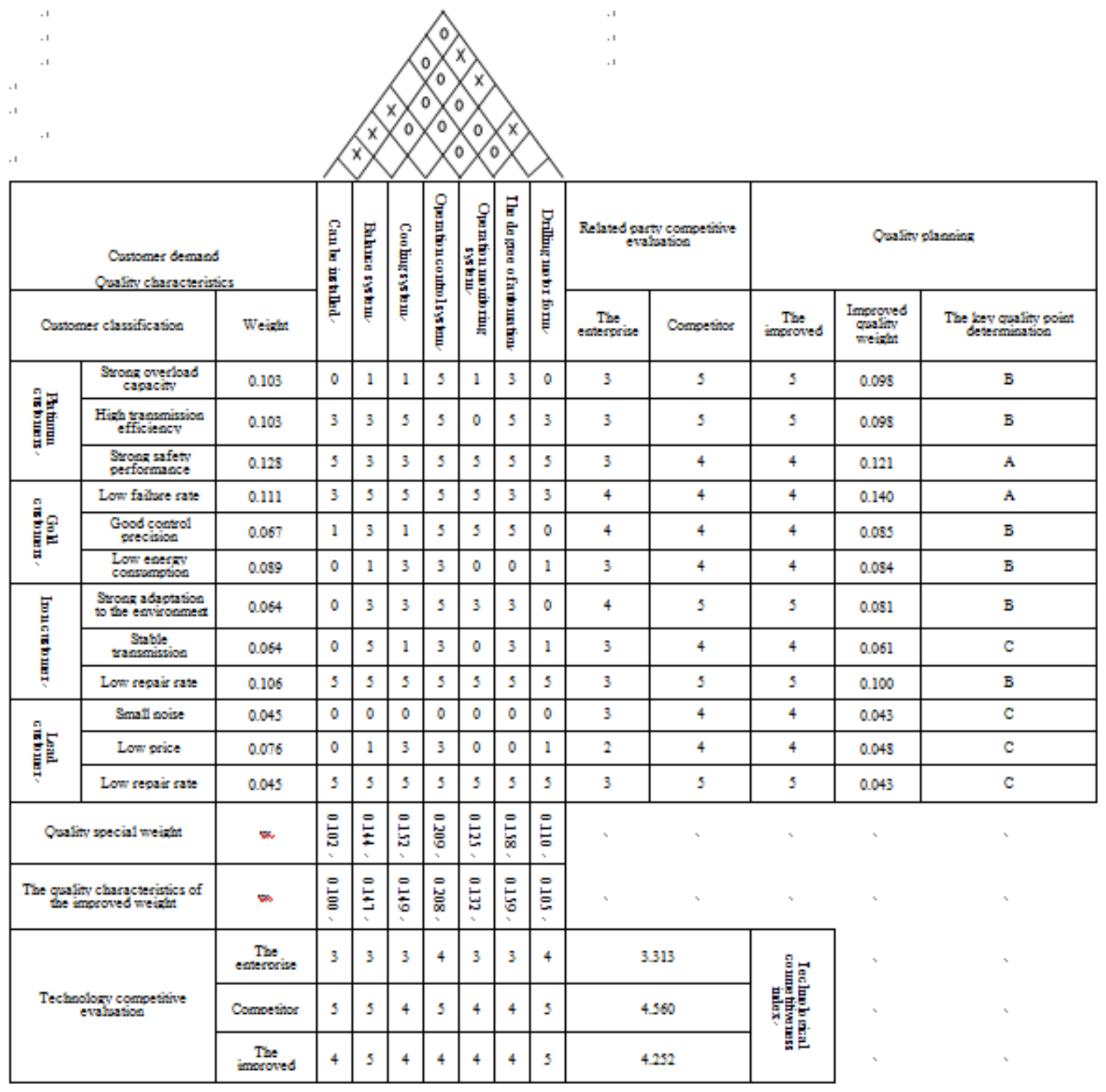

Figure 2. The development and design of constructing house of quality map 